\title{
Strategy-Making Processes towards Strategy Transformation: An Analysis of Leading High-tech Corporations in Taiwan.
}

\author{
Li-Chung Chang ${ }^{1, a}$, Xiang Li ${ }^{2, b}$, Hao Chang ${ }^{3, c}$, De-Hong Miao ${ }^{4, d}$
}

${ }^{1}$ \#1038 Guangcongroad Zhong Latan Baiyun District Guangzhou (Guangzhou Zhong Latan

University Park), China.\#1 Xueyuan Road, Zhongshan City, Guangdong province, China.

2,3,4\#1038 Guangcongroad Zhong Latan Baiyun District Guangzhou (Guangzhou Zhong Latan

University Park), China.

am13686147477@163.com, '505417792@qq.com,

'64536042@qq.com, d277192673@qq.com

Keywords: organizational change, types, decision-making process, strategy, transformation

Abstract: To respond to the environmental change is important to the competitive advantage and survival of corporation. This research seeks to develop a contingency framework on strategy transformation, providing insights into the decision making processes of organizational change.Eight hi-tech cases were studied and the findings indicate four types of strategy transformation which can be seen as four leverage strategies in nature.

\section{Introduction}

Motivation. To respond to the environmental change is important and necessary to competitive advantage and survival of corporation (Teece et al., 1997) especially in the rapid change environment means that environment has the big change degree with more factors and unpredictable .Purposes: Obviously, the world is in need of a new paradigm in decision-making process toward strategy transformation to fit the radical fluctuation among technology, market and so on, so to develop a framework (or pattern) of decision-making process toward strategy transformation is the purpose and of this research.

\section{Literature review}

Organizational change or transformation can be defined as an organization in order to adapt environmental change to change or transform itself. In addition, strategy transformation (change) refers to change strategy to adapt rapid change environment. Meanwhile, Rapid environmental change is the environment with big change degree is big and the factors are more. That is, the environment is unpredictable. Strategy transformation is the process to sense the changing phenomenon of a big scale to make the strategies of transformation .

\section{Methods}

Research design This study adopt 'theory-led' approach. Lee, Mitchell and Sablynski (1999) confirmed that basically cases study has two research approaches: theory-led or theory-generated. Theory-led means to explore, evaluate or exemplify via a theory or perspective. This study adopted multi-case study design to explore and test decision-making process toward successful strategy transformation according to the radical change environments from high-technology firms via 'replication logic' (Yin, 2008). In addition, this study adopted embedded analysis design, because 
the decision-making process includes individual, organizational and group decisions. Therefore, analysis includes these three levels. The selection of cases was 'theoretical sampling' rather than 'random sampling', because case study was focus on the useful case for the theory of 'organizational change (transformation)' to fill the theoretical gap. Therefore, theoretical sampling was to continually collect and select useful cases which is able to make theoretical replication and to extend the theory till theoretical saturation meaning no new information seems to emerge during coding. Meanwhile, during the case selection, researcher have to choose (1) cases which can exhibit predicted result or (2) cases which can predicts contrasting results but for anticipatable reasons to reach 'theoretical replication' (Yin, 2009).

Data collection This study adopted 'multi-sources' to collect data for better reliability. First was the secondary data collection from UDN, Commonwealth database and so on, then, the academic databases. Second was the collection of primary data collection. We interviewed key decision makers and their colleagues who deeply understand the transformation. A framework with structured, opened questions of interview was formed based on Daft et al s' (2010) framework of organizational change. Every interview took 1 2 hours and we recorded the interview and filed them as word by word script, then we encoded them and to make the analysis of encode reliability through different co-authors. Through cross-examine among evidence chain and other sources, a triangulation test can be made. All data were filed at the case database.

Data analysis The purpose of this research was to explore the decision-making process. Therefore, it was suitable to adopt 'time series analyses, 'pattern matching', and 'cross-case synthesis' (Yin, 2008). Through the 'multi-case design' to achieve the 'logic of replication', this research was able to find a general pattern. If the analysis of one or more cases supports the same theory, the findings exhibit theoretical replication. Such replication can enhance external validity (Yin, 2008).In the process of analysis, first was within-case analysis to find the main traits of process from single case, then to compare all cases to find decision-making process of replication. Data collection and analysis were usually synchronization. Data collection will stop until the theoretical saturation.

\section{Analysis Result}

Case 1:

Performance after transformation. Case 1 is the biggest (50\% market share and annual 30\%-40\% growth rate) and most valuable internet trading website in the listed company in Taiwan. Rapid change in environment. Case 1 was a manufacturer of phone-cost-reducer. Although Chairman of case 1 burned out money during the internet bubble, he tried and grouped a team to provide B.B.S. (Bulletin Board System) service to allow internet users to free discussion on the website. BBS become very popular in 2004. From the analysis of discussion on B.B.S., he found that people wants to 'trade' on the website. It is a good opportunity to transform.Decision-making processes: (1) Searching for a new position on the industrial structure. (2) Strengthening advantages and position. (3) Expanding via barrier building.

Case 2:

Performance after transformation. Case 2 is the biggest semi-conductor manufacturing company and the third biggest company in semi-conductor industry in the world.Rapid change in 
environment. Since case 2 built the first professional manufacture business in semi-conductor industry in the world in 1987. Many followers imitated their strategy and become their competitors. They compete in capacity, cost, and price one another. In order to keep good position and profit in the industry, Chairman of case 2 thought it needed to transform.

Decision-making processes: (1) Searching for a new position on the industrial structure. (2) Strengthening advantages and position. (3) Expanding via barrier building.

\section{Case 3:}

Performance after transformation. Case 3 brought $30 \%$ to $40 \%$ annual sales growth to the group (Taiwan), since it was established in 2010. Rapid change in environment. 'Cloud' business has become the main trend in today's business. Case 3 thought this is a good opportunity to transform and to take this trend. Decision-making processes: (1) new market segment searching to fit the new trend. (2) Development of specific and unique product to fit the segment. (3) Expanding via entering different segments in the trend.

Case 4:

Performance after transformation. Case 4 has become the first, biggest and exist-longest Chinese on-line music website, since it was established in 2004. It is the only two paid-up on-lone website with high profit in the world and Apple Computer is the other one. It owns one million paid-up members with the annual sales amount NT\$ 2 billion.Rapid change in environment. Decision-making processes: (1) new market segment searching to fit the new trend. (2) Development of specific and unique product to fit the segment. (3) Expanding via entering different segments in the trend.

Case 5:

Performance after transformation. Since entered into 'hi-technology industry' from traditional industry, case 5 has 20 times growth in sales. It has become the biggest serve slide supplier in Asia and the second in the world. Customers include HP, IBM, Dell, Sun Micro and NEC. Radical change in environment. Case 5 was a slide suppliers for furniture, since it was established in 1986. Till the year 2000, competitors from mainland China reduced $30 \%$ cost to compete and make case 5 lose more than $40 \%$ orders from American buyers. The chairman Lin thought I can't accept 30\% profit lose, but where is other way to keep on growing?

Decision-making processes: (1) extension of niche technology. (2) Adjusting technology to fit the customer needs. (3) Expanding via leveraging niche technology.

Case 6:

Performance after transformation. A leading touch panel provider. Products have been widely applied by iPhone, iPad related products. Radical change in environment. Case 6 was a glass manufacturers for architecture. Its main function was to cut and polish glasses. Because of low added-value, the profit in the traditional industry was low. Since the second generation, Zhil-Ming Zhong took over, he decided to transform to enhance the margin. Decision-making processes: (1) extension of niche technology. (2) Adjusting technology to fit the customer needs. (3) Expanding via leveraging niche technology.

Case 7:

Performance after transformation. Case 7 has become the biggest touch-solution provider who has more than 50\% market share in the world. Radical change in environment. During the era of 1990, LCD started to replace traditional iconoscope monitor. The industry was more and more competitive and the profit was very low. In 1995, an American touch panel company ELO wanted to purchase traditional monitor from Chairman of case 7 . He found that a monitor plus touch function can increase double price. He realized touch solution (technology) is the future. Therefore, he asked ELO to manufacture touch monitor for them and Chairman Jiang thought that it is a transformation opportunity. Decision-making processes: (1) industrial integration (revolution). (2) Adjusting technology to fit the potential market. (3) Expanding via leveraging technology to potential market.

Case 8:

Performance after transformation. Case 8 experienced 4 major transformations and brought them 
become the biggest manufacturer in 3C (computer, communication and consumer electronics) related products in the world, since it was established in 1974. Its average annual growth rate is $30 \%$. Radical change in environment. Chairman of case 8 believes that external environmental change rapidly is normal, so the organization needs to ready for change all the time. Therefore, case 8 experienced 4 major transformation to upgrade themselves. Decision-making processes: (1) industrial integration (revolution). (2) Adjusting technology to fit the potential market. (3) Expanding via leveraging technology to potential market.

\section{Findings}

This research finds four types of decision-making processes towards strategy transformations through induction. Each type has replication by two examples, in addition, each type has its opposite type with another two cases to reach theoretical replication.

First is 'industrial-partition-driven' strategy transformation. Case 1 and 2 are examples.

Second is a 'market (demand)-driven strategy transformation'. Case 3 and 4 are examples. Third is a 'technology-driven strategy transformation'. Case 5 and 6 are examples.Fourth is an '(industrial) integration-driven strategy transformation' Case 7 and 8 are examples.

\section{Conclusions}

To induce among the findings, conclusions can be made. First all successful high-tech corporations are flexible in transformation, when they are in the radical change environment. They can flexibly change technology or market to respond to the changing environment. Second, although they are technology or market emphasized, they will all not be 'paranoid'. Finally, this research explains how successful high-tech corporations pursuing a suitable business and functional strategy and decision-making processes according to the changing environments to sustain growth.

\section{Discussion}

Comparing previous researches, this research contribute to the advances of literatures from organizational change and transformation to strategic decision-making process of transformation especially in the radical change environment.

Focusing on firms in high-tech industry is the main limitation, because the decision-making processes can be elaborated only on such setting (rapid change environment) the. Therefore, traditional industry has not been included.

Future research can expand the field from high-tech industry to traditional industry. Meanwhile, the theory of strategy transformation can also be expanded from strategic decision maker of an organization to intra-, inter-, extra-organizational decision making.

\section{Acknowledgment}

This work was finally supported by the projects coded GDGZ14Z019;15G114;Yue Jian Gui[2015]9; Yue Cai Jian[2014]564;Yue Gao Gui[2015]72 and Yue Gao Gui[2015]72-1221.

\section{Reference}

[1] Daft, R.L., Murphy, J. and Willmott, H. (2010). Organization Theory and Design. Publisher: South-Western.

[2]Lee, T.W., Mitchell, T. R., and Sablynski, C. J. (1999) 'Qualitative research in organizational and 
vocational psychology: 1979-1999', Journal of Vocational Behavior, 55(2), 61-87.

[3]Teece, D., Pisano, G. and Shuen, A. (1997) 'Dynamic capabilities and strategic management', Strategic Management Journal, Vol.18 No.7 pp. 509-533.

[4]Yin, R. K. (2008). Case Study Research: Design and Methods, Sage Publication. 